\title{
Tanque de evapotranspiração no tratamento de esgoto sanitário na propriedade rural
}

O Tanque de evapotranspiração é composto por tanque impermeabilizado, preenchido com diferentes camadas de substrato e plantas. Devido à escassez de estudos sobre o desenvolvimento e segurança microbiológica de espécies olerícolas no TEvap, objetivou-se avaliar a composição química e microbiológica de hortaliças produzidas em diferentes posições do sistema TEvap. O Tanque foi implantado na área rural do Triângulo Mineiro/MG, com capacidade para atende quatro moradores. Gastou-se aproximadamente $\mathrm{R} \$ 1.150,00$ com materiais adquiridos na região, valor este menor ao estimado para os sistemas de fossa séptica convencional e fossa séptica biodigestora. Como resultado, verificou-se que a composição química da alface e rúcula não diferenciaram entre os cultivos nas diferentes posições do TEvap e a testemunha. Todos os coliformes encontrados nas amostras foram termotolerantes, resultando em inadequados para consumo. No início do TEvap a alface apresentou maior concentração de coliformes, contrapondo ao final do TEvap onde as amostras de alface e rúcula apresentaram uma redução acima de $50 \%$ de coliformes, entretanto a água de irrigação foi apontada como possível veículo de contaminação das olerícolas. Assim, apesar do sistema apresentar eficiência no tratamento de águas negras, deve-se preocupar também com a qualidade da água de irrigação para a produção de alimentos seguros.

Palavras-chave: Águas negras; Coliformes; Alface; Rúcula.

\section{Evapotranspiration tank in the treatment of sanitary sewage at rural property}

\begin{abstract}
The Evapotranspiration Tank consists of a waterproofed tank, filled with different layers of substrate and plants. Due to the scarcity of studies on the development and microbiological safety of vegetable species in TEvap, the objective was to evaluate the chemical and microbiological composition of vegetables produced in different positions of the TEvap system. The tank was implemented in the rural area of Triângulo Mineiro/MG, with the capacity to serve four residents. Approximately $R \$ 1,150.00$ was spent on materials purchased in the region, a value lower than that estimated for the conventional septic tank and biodigester septic tank systems. As a result, it was found that the chemical composition of lettuce and arugula did not differentiate between the crops in the different positions of TEvap and the control. All coliforms found in the samples were thermotolerant, resulting in inadequate consumption. At the beginning of TEvap, the lettuce showed a higher concentration of coliforms, in contrast to the end of TEvap where the samples of lettuce and arugula showed a reduction of more than 50\% of coliforms, however the irrigation water was pointed out as a possible vehicle of contamination of the vegetables. Thus, although the system is efficient in the treatment of black water, care should also be taken with the quality of irrigation water for the production of safe food.
\end{abstract}

Keywords: Black waters; Coliforms; Lettuce; Arugula.

Topic: Uso de Recursos Naturais

Reviewed anonymously in the process of blind peer.
Received: 03/03/2021

Approved: 26/03/2021
Diego Cesar Veloso Rezende (id

Centro Universitário Mário Palmério, Brasil

http://lattes.cnpq.br/2390623769547865

http://orcid.org/0000-0001-6176-0220

diegoformiga@yahoo.com.br

Débora Astoni Moreira

Instituto Federal Goiano, Brasil

http://lattes.cnpq.br/0892554192927049

http://orcid.org/0000-0002-8658-1269

debora.astoni@ifgoiano.edu.br

Sthefania Dalva da Cunha Veloso Rezende (it

Centro Universitário do Cerrado, Brasil

http://lattes.cnpq.br/2988384474905850

http://orcid.org/0000-0003-1616-9743

sthenutri@hotmail.com

\author{
José Antonio Rodrigues de Souza (iD) \\ Instituto Federal Goiano, Brasil \\ http://lattes.cnpq.br/1637300776838940 \\ http://orcid.org/0000-0003-3024-9424 \\ jose.antonio@ifgoiano.edu.br \\ Éllen Lemes Silva (iD) \\ Universidade Estadual do Oeste do Paraná, Brasil \\ http://lattes.cnpq.br/2020996967548069 \\ http://orcid.org/0000-0001-5649-5055 \\ ellen cbba@hotmail.com
}

\section{Referencing this:}

REZENDE, D. C. V.; MOREIRA, D. A.; REZENDE, S. D. C. V.; SOUZA, J. A. R.; SILVA, É. L.. Tanque de evapotranspiração no tratamento de esgoto sanitário na propriedade rural. Revista Ibero Americana de Ciências Ambientais, v.12, n.3, p.627-639, 2021. DOI: http://doi.org/10.6008/CBPC2179-6858.2021.003.0050 


\section{INTRODUÇÃO}

O acesso à rede de coleta ou ao tratamento de esgoto abrange $79,5 \%$ da população brasileira, de acordo com a pesquisa realizada, em 2015, pelo Instituto Brasileiro de Geografia e Estatística - IBGE. Entretanto, no estudo do IBGE foi observado que, em área rural, o acesso reduz para apenas $37,9 \%$ da população, indicando que mais de 19 milhões de moradores rurais não tem acesso à rede de coleta ou ao tratamento de esgoto sanitário.

Ainda segundo IBGE, cerca de $43,7 \%$ das residências rurais possuem sistema de tratamento do tipo fossa rudimentar ou fossa negra, sendo que outras $10,2 \%$, não contam com qualquer tipo de tratamento dos seus efluentes com qualquer tipo de tratamento.

Essa deficiência no sistema de tratamento de esgotamento sanitário transformando-se em fonte poluidora dos mananciais é fator de risco para a saúde animal e humana. De acordo com Bernardes (2014) e Scherer et al. (2016) a quantidade de esgoto sanitário lançado no solo ou em corpos d'água, em estado bruto ou incorretamente tratado, constitui expressiva carga de organismos patogênicos excretados por indivíduos infectados no ambiente. Esse quadro de deficiência sanitária tem forte impacto nos indicadores de saúde, muito abaixo dos padrões mínimos da dignidade humana em várias regiões brasileiras.

De acordo com Oliveira et al. (2018), a segregação de esgotos sanitários em sua origem simplifica o tratamento dos mesmos, por possuírem diferentes composições. Assim, o esgoto sanitário é classificado em duas classes principais: águas cinzas e negras. As águas cinzas são aquelas provenientes de pias, chuveiros e lavanderias, que podem ser reutilizadas, inclusive para irrigação de espécies ornamentais. Já as águas negras são aquelas provenientes do esgoto sanitário, contendo água, urinas e fezes, possui maior concentração de patógenos e por isso necessita de tratamento específico.

Nesse sentido, a busca por tecnologias alternativas e de baixo custo para o tratamento de efluentes com alta concentração de patógenos torna-se imprescindível para preservação ambiental. Uma tecnologia alternativa que tem sido bastante difundido em relação aos métodos convencionais é o tratamento por meio de Tanque de evapotranspiração (TEvap). De acordo com Gabialti (2009), trata-se de um sistema de fácil implantação e manejo, sendo composto por tanque impermeabilizado preenchido com diferentes camadas de materiais e plantio com espécies vegetais de crescimento rápido e elevada demanda por água. Para Galbiati (2009), Oliveira et al. (2018), o TEvap apresenta alta eficiência, baixo custo, baixo consumo de energia, tolerância à variabilidade de carga e harmonia paisagística.

Este sistema é composto por tanque impermeabilizado, preenchido com diferentes camadas de materiais e plantio com espécies vegetais de crescimento rápido e elevada demanda por água. $O$ tratamento de águas negras ocorre por meio da ação microbiana anaeróbia, promovendo a decomposição da matéria orgânica e mineralização de nutrientes contidos no esgoto. Por capilaridade a água se move para a superfície e ocorre a absorção e evapotranspiração pelas plantas, devolvendo a água limpa para o meio ambiente (PAULO et al., 2004; GALBIATI, 2009; OLIVEIRA et al., 2018).

É relatada a diversas espécies vegetais que já foram cultivadas em sistema TEvap, tais como: 
bananeiras (Musa cavendishii), taiobas (Xanthosoma sagittifolium) e plantas ornamentais como copo-deleite (Zantedeschia aethiopica); maria-sem-vergonha (Impatiens walleriana); lírio-do-brejo (Hedychium coronarium); caeté banana (Heliconia spp.) e junco (Zizanopsis bonariensis) (PAMPLONA et al., 2004; MANDAI, 2006; GALBIATI, 2009; SOUZA et al., 2018; SOUZA et al., 2019). Segundo Galbiati (2009), hortaliças como couve e tomateiro também podem ser introduzidas, porém deve se evitar plantas que tenham raízes consumidas cruas e hortaliças rasteiras.

Diante da necessidade de tratamento do esgoto sanitário das propriedades rurais, espécies olerícolas como alface (Lactuca sativa L.), rúcula (Eruca sativa L.) e rabanete (Raphanus sativus), que seriam excluídas do sistema, apresentam alta demanda por água e desenvolvimento rápido. Possuem grande aceitabilidade pelos brasileiros, são ricas em conteúdo nutricional, alta produção por área e ciclo curto, permitindo várias safras por ano (VALERIANO et al., 2016; SANTOS et al., 2018). Porém, ainda não há estudos sobre o desenvolvimento e segurança microbiológica dessas espécies no TEvap.

Embora a legislação ambiental não preveja a reutilização de águas residuárias na produção de alimentos consumidos in natura, devido ao risco sanitário, a necessidade da preservação ambiental vem, em âmbito mundial, aumentando e não permite que os resíduos sólidos, líquidos e semilíquidos das atividades humanas doméstica, industrial e agrícola sejam lançados no ambiente sem prévio tratamento. Assim, considerando que o sistema de aplicação de resíduos seja parte fundamental na viabilidade técnica e sanitária, com este trabalho, objetivou-se associar o tratamento de resíduos e o tanque de evapotranspiração com o cultivo de olerícolas.

\section{MATERIAIS E MÉTODOS}

\section{Caracterização da Área Experimental}

O sistema de tratamento TEvap foi implantado em uma propriedade rural na região do triângulo mineiro que desenvolve exclusivamente a olericultura. O relevo varia de plano a suave ondulado e o solo foi classificado como Latossolo amarelo distrófico, de acordo com os critérios da Empresa Brasileira de Pesquisa Agropecuária (EMBRAPA, 2013).

O clima predominante na região, de acordo com a classificação de Köppen, é do tipo Aw, ou seja, clima tropical, com inverno seco e verão quente e chuvoso. A precipitação no ano de 2018 foi de 1569,1mm, distribuída irregularmente e concentrada nos meses de dezembro a março.

Durante a condução do experimento foram observados o comportamento da precipitação pluviométrica, da umidade relativa do ar (UR) e temperatura. A precipitação pluviométrica alcançou um total de $412,6 \mathrm{~mm}$ de chuva, tendo como a UR uma média de $68,7 \%$. O comportamento da temperatura apresentou valor médio de 21,5 으, com temperaturas máximas de 28,4 으 C e mínimas de $16,1^{\circ} \mathrm{C}$.

\section{Construção e Implantação do Sistema TEvap}

A construção do sistema de tratamento do tanque de evapotranspiração (TEvap) foi realizado no dia 
16 de abril de 2018, e seguiu os critérios estabelecidos por Galbialti (2009) e Emater (2016), utilizando-se área de dois metros quadrados para cada usuário do sistema (GALBIATI, 2009; COSTA, 2014; EMATER, 2016).

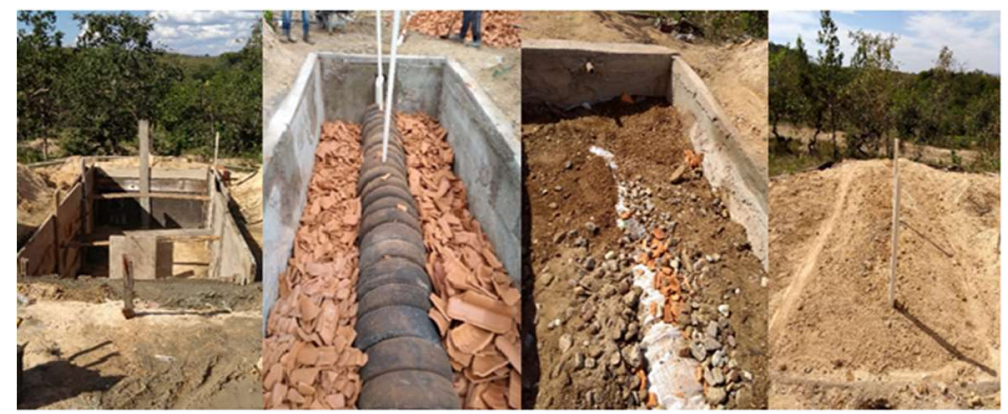

Figura 1: Etapas de implantação do TEvap.

Assim, para uma família de quatro pessoas fixas, o tanque apresentou dois metros de largura, cinco metros de comprimento e um metro de profundidade, totalizando um volume de dez metros.

Para realização dos estudos, procedeu-se a impermeabilização das laterais e do fundo do TEvap, bem como elevação das laterais, evitando-se tanto a infiltração dos escoamentos superficiais, subterrâneos e percolações. Ao centro, foram formadas uma câmara longitudinal pela colocação sucessiva e alinhadas pneus usados inteiros. A tubulação de entrada de esgoto $(100 \mathrm{~mm})$ foi posicionada de modo a direcionar o esgoto sanitário para o interior dessa câmara. O preenchimento da escavação foi realizado colocando-se camadas sucessivas de entulho cerâmico (aproximadamente $0,45 \mathrm{~m}$ ), brita 0 (aproximadamente $0,10 \mathrm{~m}$ ), areia lavada (aproximadamente $0,10 \mathrm{~m}$ ) e o restante, com o solo do horizonte escavado. Na saída do tanque, 0,10 m abaixo do nível do solo, colocou-se uma tubulação de $50 \mathrm{~mm}$ para funcionar com tubo extravasor (Figura 1).

Após a construção do tanque, na superfície, foram transplantadas mudas de três espécies de hortaliças: alface, rabanete e rúcula.

\section{Custo do Projeto}

A construção do TEvap avaliado foi participativa e houve doações através de parceiros locais. O valor total investido na construção do sistema foi de $\mathrm{R} \$ 319,85$ (Tabela 1).

Tabela 1: Materiais utilizados para construção do TEvap e seus custos (R\$̦).

\begin{tabular}{|c|c|c|c|c|c|}
\hline Descrição & Unidade & Quantidade & Valor unitário & Custo total & Valor investido \\
\hline Tubulação $100 \mathrm{~mm}$ & barra & 1 & 41,90 & 41,90 & 41,90 \\
\hline Joelho esgoto $100 \mathrm{~mm}$ & $\mathrm{pç}$ & 2 & 2,99 & 5,98 & 5,98 \\
\hline Te $100 \mathrm{~mm}$ & pç & 1 & 6,89 & 6,89 & 6,89 \\
\hline Tampão 100mm & unid & 1 & 3,79 & 3,79 & 3,79 \\
\hline Tampão 50mm & unid & 1 & 2,19 & 2,19 & 2,19 \\
\hline Tela viveiro & $\mathrm{mt}$ & 25 & 6,29 & 157,23 & 157,23 \\
\hline Impermeabilizante $18 \mathrm{~L}$ & $\mathrm{~L}$ & 1 & 74,99 & 74,99 & 74,99 \\
\hline Tubulação PVC 50mm & barra & 1 & 26,89 & 26,89 & 26,89 \\
\hline Cacos de telha & $\mathrm{t}$ & 1,3 & 20,00 & 26,00 & Doação \\
\hline Areia/cascalho/brita & $\mathrm{m}^{3}$ & 6 & 90,00 & 540,00 & Doação \\
\hline Pneus aro 15 & un & 26 & 0,00 & 0,00 & Doação \\
\hline Mudas hortaliças & un & 816 & 0,04 & $32,64 *$ & Doação \\
\hline Mão de obra (pedreiro+servente) & dia & 1 & 220,00 & 220,00 & Participativa \\
\hline Total (R\$) & & & & $1.138,50$ & 319,85 \\
\hline
\end{tabular}

*Fica a critério do produtor a escolha de qual tipo de planta a ser introduzida.

\section{Delineamento dos Experimentos}


Para avaliar a eficiência do tanque e a qualidade das hortaliças no TEvap, foram cultivadas na superfície do tanque três espécies olerícolas com alta demanda de água e rápido desenvolvimento, sendo alface (Lactuca sativa), rabanete (Raphanus sativus) e rúcula (Eruca vesicaria). As três espécies são amplamente cultivadas na região pelo alto potencial olerícola.

O transplantio das mudas de alface foi realizado no dia 20 de setembro e sua colheita no dia 05 de novembro, 46 dias após o transplantio (DAT). Foi utilizada a cultivar Betty, do grupo das alfaces americanas (SALA et al., 2012). Essa cultivar é caracterizada por folhas grandes, uniforme, com alto volume de massa, tolerante ao pendoamento precoce, tendo seu ciclo em até 70 dias.

As mudas de rúcula foram transplantadas sete dias após a alface e sua colheita também foi realizada no dia 05 de novembro, 39 DAT. O cultivar empregado foi o Selecta, que possui folhas largas e compridas, levemente recortadas, de coloração verde escuro. Comprimento médio $22-25 \mathrm{~cm}$ e largura média 6-7 cm. Sabor levemente pujante. 0 ciclo varia entre 40 a 50 dias.

Já no dia 04 de outubro, foi realizado o transplantio do rabanete, cultivar Coral, o qual apresenta porte alto com um sistema radicular redondo de coloração externa vermelha e polpa branca, com adaptação a temperaturas amenas e frias com um ciclo entre 30-40 dias. Devido ao ataque severo de formigas, não foi possível realizar a coleta do rabanete plantado.

A adubação de base foi realizada utilizando apenas adubo orgânico, na dose de $4 \mathrm{~kg} \mathrm{~m}^{-2}$ de esterco bovino. Os tratos culturais foram realizados conforme o recomendado para cada cultura conforme Filgueira (2012) e ABCSEM (2015).

\section{Irrigação}

Foi necessário o emprego de irrigação devido ao baixo índice pluviométrico e alta temperatura e evapotranspiração, sendo realizada irrigação por meio de regador manual, utilizando água de uma nascente próxima a residência.

\section{Análise da água de irrigação}

Para a caracterização físico-química e microbiológica da água de irrigação foi coletada amostra de água da nascente responsável pelo fornecimento., sendo analisados $\mathrm{pH}$, condutividade elétrica (CE), turbidez, oxigênio dissolvido (OD), fósforo, nitrato, nitrogênio total, coliformes totais e termotolerantes, conforme metodologias descritas em metodologias de APHA et al. (2012). Na Tabela 2, estão apresentados os resultados da caracterização da água de irrigação.

Tabela 2: Caracterização da água de irrigação.

\begin{tabular}{llll}
\hline Parâmetro & Teor & Padrão CONAMA & Unidade \\
\hline pH & 4,9 & $6,0-9,0$ & -- \\
CE & 48,1 & -- & $\mu S / c m$ \\
Turbidez & 34,5 & $\leq 40$ & NTU \\
OD & 5,1 & $\geq 6$ & mg.L-1 \\
Temperatura & 26,5 & -- & ${ }^{\circ} \mathrm{C}$ \\
Nitrogênio total & 12,7 & $\leq 3,7$ & $\mathrm{mg}^{-\mathrm{kg}^{1}}$
\end{tabular}




$\begin{array}{llll}\text { Nitrato } & 12,6 & \leq 10 & \text { mg.L-1 } \\ \text { Fósforo } & 0,6 & \leq 0,1 & \text { mg.L-1 } \\ \text { Coliformes termotolerantes } & 261,3 & \leq 200 & \text { NMP.100mL-1 } \\ \text { Coliformes totais } & 275,5 & -- & \text { NMP.100mL-1 }\end{array}$

Fonte: CONAMA (2005).

\section{Delineamento das Hortaliças}

\section{Análises Químicas}

Para avaliar a relação do sistema TEvap com a composição química das hortaliças, foram coletadas amostras da alface (46 DAT) e rúcula (39 DAT) no dia 05/11/2018 e determinada: \% de massa seca; pH; condutividade elétrica (CE); fósforo e nitrogênio total, de acordo com as metodologias de APHA et al. (2012).

\section{Análises Microbiológicas}

Foram realizadas as análises microbiológicas para verificação da contaminação por coliformes nas folhas de alface e rúcula. Para determinação de coliformes totais e termotolerantes nas alfaces e rúcula foi utilizado o método de tubos múltiplos. As amostras da alface e rúcula foram separadas assepticamente, aliquotadas em $10 \mathrm{~g}$ de cada espécie, trituradas e homogeneizadas em liquidificador estéril, $10 \mathrm{~g}$ da amostra com $90 \mathrm{~mL}$ de água peptonada $0,1 \%$, obtendo a diluição $10^{-1}$, sendo em seguida preparadas às diluições $10^{-2}$ e $10^{-3}$.

Para todas as amostras analisadas, a determinação do número mais provável de coliformes pelo método dos tubos múltiplos foi realizada utilizando Caldo Lauril (fabricante Himedia), Sulfato de Sódio-CLS e Caldo Lactosado Bile Verde Brilhante-CLBVB (fabricante Alere). Para determinação de coliformes termotolerantes foi empregado Caldo E.C. Broth (fabricante Himedia). Alíquotas de 1,0 mL de cada diluição, foram transferidas para séries de três tubos contendo CLS com tubos de Durham invertidos. Os tubos foram incubados a $35 \pm 1$ 으 C durante 24 e $48 \mathrm{~h}$, e uma alçada de cada tubo apresentando crescimento e produção de gás foi semeada em tubos contendo $10 \mathrm{~mL}$ de CLBVB e E.C., com tubos de Durham invertidos. Os tubos contendo CLBVB foram incubados a 35ㄷ por 24 e 48 h, enquanto tubos de E.C. foram incubados por 24 e 48 $\mathrm{h}$ a $45 \circ \mathrm{C}$ em banho maria. A formação de gás nos tubos de CLBVB indicou a presença de coliformes totais e nos tubos E.C. presença de termotolerantes, sendo o resultado expresso em NMP de coliformes totais por grama de alimentos.

\section{Análises Estatísticas}

O delineamento experimental utilizado foi blocos casualizados (DBC) com 4 repetições e 6 tratamentos em esquema fatorial. Os tratamentos foram: 3 posições no TEvap (inicial, final e testemunha) $x$ 2 espécies olerícolas (alface e rúcula). O DBC foi utilizado para as variáveis químicas analisadas na colheita (massa seca; $\mathrm{pH}$; condutividade elétrica; fósforo, nitrogênio total), e tiveram suas médias comparadas pelo teste de Tukey ( $5 \%$ de significância) para cada espécie olerícola.

Cada $1 \mathrm{~m}^{2}$ do TEvap constituiu uma parcela, foram descartados $2 \mathrm{~m}^{2}$ centrais do sistema. Fora do sistema, foram instaladas as parcelas testemunhas. Cada parcela foi subdivida em 3 subparcelas (alface, 
rúcula e rabanete). Entretanto, as subparcelas de rabanete foram perdidas. Assim, foram considerados, para fins estatísticos, apenas 24 subparcelas ( 3 posições no TEvap $\times 2$ espécies $\times 4$ blocos) (Figura 2).

Os dados obtidos foram submetidos à análise de variância (ANOVA), teste F, teste de Tukey e análise de regressão, através do programa SISVAR 5.0 (DEX/UFLA) (FERREIRA, 2010).

Quando o quadrado médio de tratamentos foi significativo pelo teste $F$ ( $5 \%$ de probabilidade), realizou-se a análise de regressão em função do tempo após de transplantio, definindo o melhor ajuste segundo a combinação de significância e maior coeficiente de determinação. Quando houve efeito da espécie, foi aplicado o teste de Tukey (5\% de significância) para comparação de médias.

As médias do número mais provável (NMP) de coliformes termotolerantes e coliformes totais utilizou-se o Delineamento Inteiramente Casualizado (DIC) em esquema de parcelas subdivididas com duas repetições (alface e rúcula), amostrando-se 68 plantas por parcela, com um tratamento (testemunha) também com parcelas, sendo eles: T1 - início do tanque; T2 - final do tanque e T3 - testemunha (Figura 2).

As análises estatísticas também foram submetidas ao teste de médias e à análise de variância empregando o teste Tukey ao nível de $5 \%$ de probabilidade com o auxílio de software estatístico SISVAR 5.0 (DEX/UFLA) (FERREIRA, 2010).

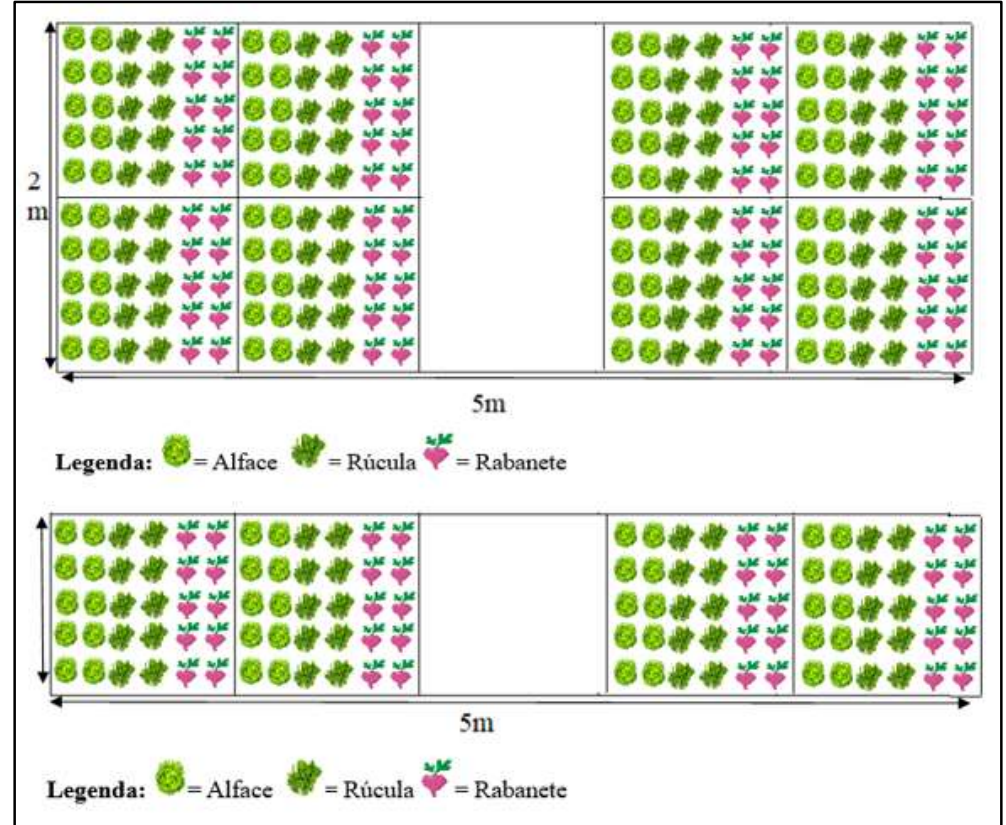

Figura 2: Delineamento experimental utilizado no TEvap, contendo as parcelas e subparcelas dos três cultivares transplantados.

\section{RESULTADOS E DISCUSSÃO}

O experimento foi desenvolvido no período de 157 a 203 dias após a instalação do sistema, época que operava dentro da sua capacidade. O volume total útil estimado do TEvap implantado é de $3.082 \mathrm{~L}$, sendo 2.480 L no conjunto câmara de pneus e 602 L correspondem a água retida por capilaridade nos materiais de enchimento e substratos do tanque. Estas informações são confirmadas por Galbiati (2009), onde encontrouse o volume útil total para um tanque de $4 \mathrm{~m}^{2}$ (área superficial) de $1.233 \mathrm{~L}$, dos quais, $992 \mathrm{~L}$ eram ocupados pela água livre e $241 \mathrm{~L}$ nos materiais porosos. 
Bernardes (2014) relata que o tempo de detenção hidráulica (TDH) no TEvap varia de 24,5 a 90 dias, com valor médio de 50,7 dias, sendo 18,2 dias para a câmara e 32,5 dias para o filtro, para um sistema de 4 $\mathrm{m}$ de comprimento e dois habitantes na residência.

O custo previsto para o TEvap é de aproximadamente $\mathrm{R} \$ 1.150,00$ para a região do Triângulo Mineiro (Tabela 1). Entretanto, a construção participativa, a utilização de materiais obtidos in loco e o apoio de entidades públicas minimizaram esse custo em $72 \%$. Para a construção do sistema, foram gastos menos de trezentos e vinte reais. Assim, o sistema se demonstra viável economicamente até mesmo para comunidades rurais de baixa renda.

Na Tabela 3 pode ser analisado o custo de diferentes sistemas de tratamento de águas negras, como base os preços do Sistema Nacional de Pesquisa de Custos e Índices da Construção Civil (SINAPI), data base outubro de 2019, desonerado, para o estado de Minas Gerais.

Tabela 3: Valores das composições para tratamento de efluentes para quatro moradores - SINAPI, out/2019.

\begin{tabular}{lll}
\hline $\begin{array}{l}\text { Código } \\
\text { INAPI* }\end{array}$ & Descrição da composição & $\begin{array}{l}\text { Valor } \\
\text { (R\$) }\end{array}$ \\
\hline 98052 & $\begin{array}{l}\text { Tanque séptico circular, em concreto pré-moldado, diâmetro interno =1,10 m, altura interna }=2,50 \mathrm{~m}, \\
\text { volume útil: } 2138,2 \text { I }\end{array}$ & 984,17 \\
98066 & $\begin{array}{l}\text { Tanque séptico retangular, em alvenaria com tijolos cerâmicos maciços. Dimensões: } 1,0 \times 2,0 \times 1,4 \mathrm{~m}, \\
\text { volume útil: } 2000 \text { I }\end{array}$ & $3.190,57$ \\
98072 & $\begin{array}{l}\text { Filtro anaeróbio retangular, em alvenaria com tijolos cerâmicos maciço. Dimensões: } 0,8 \times 1,2 \times 1,67 \mathrm{~m}, \\
\text { volume útil: } 1152 \text { I }\end{array}$ & $2.676,10$ \\
98078 & $\begin{array}{l}\text { Sumidouro retangular, em alvenaria com tijolos cerâmicos maciços. Dimensões: } 0,8 \times 1,4 \times 3,0 \mathrm{~m}, \text { área } \\
\text { de infiltração: } 13,2 \mathrm{~m}^{2}\end{array}$ & $2.654,41$ \\
\hline
\end{tabular}

*SINAPI - Sistema Nacional de Preços e Índices para a Construção Civil.

Os custos para a construção de todo o sistema TEvap quando comparado ao sistema individual de tratamento de esgoto doméstico comumente utilizado, para o mesmo número de pessoas em relação à fossa séptica (tanque séptico + sumidouro) são $68 \%$ menores, se utilizado o tanque séptico de menor valor. Já quando comparado ao sistema biodigestor (tanque séptico + filtro anaeróbico + sumidouro), que pode custar cerca de $\mathrm{R} \$ 6.300,00$, mesmo utilizando a opção de menor valor nesse sistema, o TEvap custa $82 \%$ mais barato, além de ser de fácil instalação e manejo.

Quanto à instalação do TEvap, o mesmo se mostra menos oneroso, sendo uma boa solução para pequenos produtores que não apresentam um sistema de tratamento de esgoto em sua propriedade. Ressalta-se ainda que os valores expostos na Tabela 4, não abrangem os custos referentes ao frete e nem a instalação desses sistemas. Deste modo quando estes forem adicionados para obtenção do valor final de implementação do Tanque, esses valores poderão subir notadamente fortificando ainda mais a ideia de o TEvap ser econômico.

Todos os sistemas citados apresentam um benefício em relação ao TEvap, devido a estes poderem receber águas cinzas (originadas de pias, tanques e chuveiros), desde que seja instalado uma caixa de gordura ao sistema, pois o TEvap é indicado apenas para águas negras, oriundas de vasos sanitários.

\section{Composição Químicas das Hortaliças}

No período de funcionamento do TEvap, o sistema não proporcionou alteração no teor de matéria 
seca, $\mathrm{pH}$, condutividade elétrica ( $\mathrm{CE}$ ), e no teor nutricional (fósforo e nitrogênio total) da alface e rúcula. Sendo que da alface o valor de fósforo recomendado é de $19 \mathrm{mg} / 100 \mathrm{~g}$ e da rúcula $25 \mathrm{mg} / 100 \mathrm{~g}$ (TACO, 2014). Portanto, nessa fase de funcionamento, o cultivo no TEvap, independentemente da posição no sistema, manteve as características químicas do alimento.

Tabela 4: Composição química de alface e rúcula cultivadas nas posições inicial, final e fora do TEvap.

\begin{tabular}{|c|c|c|c|c|c|c|c|c|c|c|}
\hline \multirow[t]{2}{*}{ Tratamento } & \multicolumn{2}{|c|}{$\begin{array}{l}\text { Matéria Seca } \\
\%\end{array}$} & \multicolumn{2}{|l|}{$\begin{array}{l}\mathrm{pH} \\
- \\
\end{array}$} & \multicolumn{2}{|c|}{$\begin{array}{l}\text { CE } \\
\mathrm{mS} . \mathrm{cm}^{-1}\end{array}$} & \multicolumn{2}{|c|}{$\begin{array}{l}\text { Fósforo } \\
\text { mg.L-1 }^{-1}\end{array}$} & \multicolumn{2}{|c|}{$\begin{array}{l}\text { Nitrogênio total } \\
\text { mg.L-1 }\end{array}$} \\
\hline & Alface & Rúcula & Alface & Rúcula & Alface & Rúcula & Alface & Rúcula & Alface & Rúcula \\
\hline Início TEvap & 4,9 & 9,8 & 6,1 & 6,5 & 530,1 & 2044,8 & 0,057 & 0,048 & 6,2 & 7,8 \\
\hline Final TEvap & 5,1 & 10,5 & 6,1 & 6,4 & 597,0 & 1363,0 & 0,048 & 0,070 & 7,3 & 6,0 \\
\hline Testemunha & 4,0 & 8,3 & 5,9 & 6,6 & 430,1 & 1644,0 & 0,067 & 0,052 & 5,6 & 7,9 \\
\hline CV & 15,7 & 23,3 & 3,4 & 2,9 & 25,2 & 24,5 & 56,8 & 44,1 & 17,2 & 15,7 \\
\hline $\mathrm{DP}$ & 0,47 & 0,91 & 0,09 & 0,08 & 68,58 & 279,7 & 0,007 & 0,001 & 0,70 & 0,87 \\
\hline
\end{tabular}

As médias não diferem significativamente entre si, a $5 \%$ de probabilidade, pelo teste de Tukey.

A composição química das plantas pode ser alterada com a utilização de matéria orgânica, dependendo entre outros fatores, da fertilidade do solo, das características do material orgânico e da quantidade (OLIVEIRA et al., 2018). De acordo com este autor supracitado, os esgotos sanitários domésticos apresentam alta concentração de minerais (5-25 mg L-1 de fósforo e 35-70 mg- ${ }^{1} \mathrm{~L}$ de nitrogênio total) e pH próximo ao neutro $(6,7-7,5)$.

Não foi possível localizar na literatura recomendação de teores adequados para as folhas de rúcula. Por esse motivo, fez-se uso de dados fornecidos por Fonseca (2013) para rabanete, pelo fato de ser uma cultura da mesma família botânica e também por esta olerícola ter sido utilizada no experimento. Neste caso, os teores adequados são: nitrogênio 30 a $60 \mathrm{~g} \mathrm{~kg}^{-1}$ e fósforo 3 a $7 \mathrm{~g} \mathrm{kg-}{ }^{1}$.

Também não foi encontrado nenhuma análise quanto a condutividade elétrica na parte vegetal das hortaliças, porém afirma-se que a condutividade elétrica mede a concentração de sais dissolvidos tanto na água, no solo e nas plantas. Quando os nutrientes são consumidos pelas plantas, o valor da condutividade elétrica fica baixo. Ocorre perda de água por evapotranspiração, a concentração de sais aumenta e, consequentemente, a condutividade elétrica se eleva. Os principais sais que contribuem para a condutividade sobretudo na água são os sais de potássio, sódio, cálcio, magnésio na forma de sulfatos, cloretos, carbonatos e bicarbonatos.

Para Eucalyptus grandis, Silva et al. (2008) observaram que as concentrações foliares de todos os nutrientes de plantas tratadas com lodo de esgoto granulado mantiveram-se dentro dos limites observados usualmente nas plantações comerciais, não havendo sinais de desequilíbrio nutricional. Houve ainda incremento na concentração de fósforo. Entretanto, fazem necessários estudos da composição química de hortaliças em sistemas TEvap.

\section{Avaliação Microbiológica}

O número mais provável (NMP) de coliformes termotolerantes em todas as amostras de alface e rúcula foram iguais ao de coliformes totais, assim todos os coliformes presentes nas amostras são termotolerantes. Houve interação significativa pelo teste $F(p=0,040)$ entre as posições no TEvap e as 
espécies cultivadas para todos os teores de coliformes termotolerantes (Tabela 5).

Tabela 5: Número mais provável (NMP.g- ${ }^{-1}$ ) de coliformes termotolerantes em hortaliças cultivadas em função da posição no TEvap.

\begin{tabular}{|c|c|c|c|c|}
\hline \multirow{2}{*}{ Tratamento } & \multicolumn{4}{|l|}{ Espécie } \\
\hline & Alface & & Rúcula & \\
\hline Início TEvap & 1100,0 & $\mathrm{bA}$ & 780,0 & $b B$ \\
\hline Final TEvap & 115,5 & $\mathrm{aA}$ & 305,0 & $\mathrm{aA}$ \\
\hline Testemunha & 150,0 & $\mathrm{aA}$ & 150,0 & $\mathrm{aA}$ \\
\hline CV & 41,9 & 34,7 & & \\
\hline DP & 456,1 & 268,03 & & \\
\hline
\end{tabular}

Médias seguidas de mesma letra minúscula na coluna e maiúscula na linha, não diferem significativamente entre si, a $5 \%$ de probabilidade, pelo teste de Tukey.

Para ambas as espécies estudadas o teor de contaminação foi maior no início do TEvap. Não houve diferença significativa na contaminação entre os cultivos no final do TEvap e a testemunha, demonstrando a eficiência do sistema no tratamento do esgoto doméstico e redução na contaminação de vegetais. Tal redução total de coliformes era esperada, uma vez ao longo do sistema ocorre a redução do nível de material orgânico. Vilar et al. (2019) comprovaram a eficácia do que o sistema de tratamento TEvap na redução de coliformes. Eles observaram a redução de $99,993 \%$ dos coliformes no efluente final (150 no efluente bruto da suinocultura para $11 \times 10^{-3}$ coliformes termotolerantes $/ 100 \mathrm{~mL}$ ).

As duas culturas diferenciaram quanto a contaminação por coliformes apenas no início do TEvap, onde a alface apresentou maior NMP de coliformes. Portanto, se for cultivar as hortaliças deve-se dar preferência a parte final do sistema, onde a alface apresentou menor nível de contaminação em relação a rúcula. A Resolução RDC no 12 de 2001, prevê o limite de tolerância de coliformes a termotolerantes de $10^{2}$ NMPg- ${ }^{1}$ por amostra (ANVISA, 2001). A Tabela 6 apresenta a condição de contaminação das amostras avaliada.

Tabela 6: Contaminação da alface e rúcula coliformes termotolerantes em função da posição no TEvap.

\begin{tabular}{|c|c|c|c|c|c|c|}
\hline \multirow{2}{*}{ Espécie } & \multirow{2}{*}{ Tratamento } & \multirow{2}{*}{ Combinação de tubos } & \multirow{2}{*}{ NMP.g - ${ }^{1}$} & \multicolumn{2}{|c|}{ Intervalo de confiança (95\%) } & \multirow[t]{2}{*}{ Condição } \\
\hline & & & & Mínimo & Máximo & \\
\hline Alface & Início TEvap & $3-3-3$ & $>1100$ & 420 & - & Inadequado \\
\hline Alface & Início TEvap & $3-3-3$ & $>1100$ & 420 & - & Inadequado \\
\hline Alface & Início TEvap & $3-3-3$ & $>1100$ & 420 & - & Inadequado \\
\hline Alface & Início TEvap & $3-3-3$ & $>1100$ & 420 & - & Inadequado \\
\hline Alface & Final TEvap & $3-2-2$ & 210 & 40 & 430 & Inadequado \\
\hline Alface & Final TEvap & $2-2-0$ & 21 & 4,5 & 42 & Adequado \\
\hline Alface & Final TEvap & $3-2-2$ & 210 & 40 & 430 & Inadequado \\
\hline Alface & Final TEvap & $2-2-0$ & 21 & 4,5 & 42 & Adequado \\
\hline Alface & Testemunha & $3-2-1$ & 150 & 37 & 420 & Inadequado \\
\hline Alface & Testemunha & $3-2-1$ & 150 & 37 & 420 & Inadequado \\
\hline Alface & Testemunha & $3-2-1$ & 150 & 37 & 420 & Inadequado \\
\hline Alface & Testemunha & $3-2-1$ & 150 & 37 & 420 & Inadequado \\
\hline Rúcula & Início TEvap & $3-3-2$ & 1100 & 180 & 4100 & Inadequado \\
\hline Rúcula & Início TEvap & $3-3-1$ & 460 & 90 & 2000 & Inadequado \\
\hline Rúcula & Início TEvap & $3-3-2$ & 1100 & 180 & 4100 & Inadequado \\
\hline Rúcula & Início TEvap & $3-3-1$ & 460 & 90 & 2000 & Inadequado \\
\hline Rúcula & Final TEvap & $3-2-1$ & 150 & 37 & 420 & Inadequado \\
\hline Rúcula & Final TEvap & $3-3-1$ & 460 & 90 & 2000 & Inadequado \\
\hline Rúcula & Final TEvap & $3-2-1$ & 150 & 37 & 420 & Inadequado \\
\hline Rúcula & Final TEvap & $3-3-1$ & 460 & 90 & 2000 & Inadequado \\
\hline Rúcula & Testemunha & $3-2-1$ & 150 & 37 & 420 & Inadequado \\
\hline Rúcula & Testemunha & $3-2-1$ & 150 & 37 & 420 & Inadequado \\
\hline Rúcula & Testemunha & $3-2-1$ & 150 & 37 & 420 & Inadequado \\
\hline
\end{tabular}


Observou-se que $100 \%$ das hortaliças cultivadas na parte inicial do TEvap apresentaram níveis de contaminação de coliformes termotolerantes inadequados para o consumo humano (Tabela 6). Na parte final do TEvap, 50\% das amostras de alface estavam adequadas para o consumo, enquanto todas as amostras de rúcula estavam inadequadas.

Tonetti et al. (2018) relata estudos, que mostram alguns alimentos e folhas que crescem no TEvap, destaque para bananas e taiobas, estes não sofreram nenhum tipo de contaminação por bactérias e outros micro-organismos e, portanto, são seguros para o consumo humano. No entanto alerta que não é recomendado o consumo de raízes (ex: inhame ou gengibre) ou frutos colhidos do chão do TEvap.

Entretanto as duas espécies cultivadas fora do TEvap, testemunha, apresentaram 100\% das amostras inadequadas ao consumo humano. Assim, a fonte de contaminação encontrada nos tratamentos cultivados no TEvap não foi exclusivamente a água residuária presente nele.

Constatou-se que água de irrigação utilizadas no experimento estavam contaminadas por coliformes termotolerantes, apresentando 261,3 e 275,5 NMP $100 \mathrm{~mL}^{-1}$ de coliformes termotolerantes e totais, respectivamente (Tabela 3). Assim apresenta-se em desacordo com a legislação, pois a norma do CONAMA no 357 (2005) estabelece o limite de tolerância 200 NMP 100 mL-1 para coliformes termotolerantes em água de irrigação de hortaliças consumidas cruas.

Observa-se no trabalho que a amostra de nitrato se apresentou acima do estabelecido pelo CONAMA, ele é tóxico aos seres humanos. O nitrato juntamente com o fósforo na água torna-se um contaminante. Entre as fontes de fósforo destacam-se os esgotos domésticos, da própria matéria fecal. Estes dois nutrientes em excesso causam um crescimento excessivo das algas, processo conhecido como eutrofização, o que pode prejudicar o abastecimento público, a recreação e a preservação da vida aquática (ANA, 2008).

A água de irrigação foi possivelmente o principal veículo de contaminação das hortaliças. Vários estudos no Brasil têm identificado hortaliças com elevado grau de contaminação por coliformes transmitidos pela água de irrigação. Souto (2005), Abreu et al. (2010), Araújo et al. (2015) e Silva et al. (2016), demonstraram que a água de irrigação foi o foco de contaminação das hortaliças avaliadas. Esses estudos também observaram elevado percentual de contaminação microbiológica, com índices de coliformes termotolerantes inaceitáveis pela legislação vigente para coliformes totais quanto para coliformes termotolerantes.

Em circunstâncias ideais, a água potável não deve conter microrganismos patogênicos e nem bactérias indicadoras de contaminação fecal. Normalmente a qualidade microbiológica da água potável é avaliada de forma indireta por meio de indicadores de contaminação por coliformes. A quantidade destes microrganismos indica o grau de contaminação, e consequentemente o risco potencial quanto à presença de patógenos. Logo deve atentar que durante a irrigação nas lavouras e hortas, principalmente por aspersão, onde molha a planta toda, estes organismos são depositados nos frutos, folhas e caules das plantas (MAROUELLI et al., 2014). 


\section{CONCLUSÕES}

As hortaliças cultivadas ao longo do Tanque de Evapotranspiração (TEvap), no primeiro ano de funcionamento, tiveram bom desenvolvimento e mantiveram a composição química das cultivadas fora do sistema (testemunha). Contudo são escassos os trabalhos com a associação do TEvap e a produção de olerícolas.

A parte final do TEvap proporcionou menor contaminação por coliformes termotolerantes que a parte inicial e não diferiu do cultivo fora do sistema. Assim, o sistema TEvap é eficiente para tratamento de esgoto doméstico, porém deve ser observada a qualidade dos demais agentes passíveis de contaminação, como a água de irrigação utilizada para o manejo das olerícolas.

A construção do TEvap de forma participativa, com envolvimento de vários atores sociais, se torna fundamental para o baixo custo de implantação, sendo uma metodologia de desenvolvimento sustentável para a promoção da inclusão sócio-produtiva. Atrelado a preservação do meio ambiente, manutenção do solo e de recursos hídricos.

Recomenda-se na construção do TEvap sua completa impermeabilização, utilização da cartilha ofertada aos produtores rurais pela EMATER e o acompanhamento de um extensionista, para que este possa dar orientações durante a sua construção.

Novas pesquisas devem ser realizadas, uma vez que o TEvap é um sistema recente implantado no Brasil, deve se adequar à realidade local onde a tecnologia social será implementada para que se tenha uma solução efetiva dos problemas citados ao longo deste artigo.

\section{REFERÊNCIAS}

ABCSEM. Associação Brasileira do Comércio de Sementes e Mudas. Manual Técnico Cultivo de Hortaliças 2015. 3 ed. ABCSEM, 2015.

ABREU, I. M. O.; JUNQUEIRA, A. M. R.; PEIXOTO, J. R.; OLIVEIRA, S. A.. Qualidade microbiológica e produtividade de alface sob adubação química e orgânica. Ciência e Tecnologia de Alimentos, v.30, n.1, p.108-118, 2010.

ANA. Agência Nacional das Águas. Indicadores de qualidade: índice de qualidade das águas (IQA). ANA, 2008.

ANVISA. Agência Nacional de Vigilância Sanitária. Resolução RDC n. 12, de 02 de janeiro de 2001. Aprova o Regulamento Técnico sobre padrões microbiológicos para alimentos. Brasília: ANVISA, 2001.

APHA; AWWA; WEF. American Public Health Association; American Water Works Association; Water Environment Federation. Standard Methods for the Examination of Water and Wastewater. 21 ed. Washington: APHA, 2012.

ARAÚJO, F. V.; VIEIRA, L.; JAYME, A.; MIRANDA, M.; CONCEIÇÃO NUNES, M.; CORTÊS, M.. Avaliação da qualidade da água utilizada para irrigação na bacia do Córrego Sujo, Teresópolis, RJ. Cadernos Saúde Coletiva, v.23, n.4, 2015.

BERNARDES, F. S.. Avaliação do tratamento domiciliar de águas negras por um Tanque de Evapotranspiração (TEvap). Revista Especialize On-line IPOG, Goiânia, v.01, n.007, 2014.

CONAMA. Conselho Nacional do Meio Ambiente. Resolução n. 357, de 17 de março de 2005. Classifica as águas doces, salobras e salinas e especifica os parâmetros e limites associados aos níveis de qualidade requeridos para seu aproveitamento. Brasília: DOU, 2005.

COSTA, A. P.. Estudo de tecnologias sociais visando o tratamento do esgoto doméstico de unidade unifamiliar: Assentamento Nova São Carlos - São Carlos/SP. Monografia (Bacharelado em Engenharia Ambiental) - Escola de Engenharia de São Carlos da Universidade de São Paulo, São Paulo, 2014.

EMATER. Empresa de Assistência Técnica e Extensão Rural. Tanque de evapotranspiração para o tratamento de efluentes do vaso sanitário. Belo Horizonte: EMATER, 2016.

EMBRAPA. Empresa Brasileira de Pesquisa Agropecuária. Sistema brasileiro de classificação de solos. 3 ed. Brasília: EMBRAPA, 2013.

FERREIRA, D. F.. SISVAR-programa estatístico. Versão 4.2. 2010

FONSECA, J. O. G.. Desempenho agronômico de alface e 
rúcula em função de doses de composto fermentado em condições de cultivo protegido, sob manejo orgânico em Nova Friburgo, RJ. Dissertação (Mestrado em Agricultura Orgânica) - Universidade Federal Rural do Rio De Janeiro, Seropédica, 2013.

FILGUEIRA, F. A. R.. Novo manual de oliveira: agrotecnologia moderna na produção e comercialização de hortaliças. 3 ed Viçosa: UFV, 2012.

GALBIATI, A. F.. Tratamento domiciliar de águas negras através de tanque de evapotranspiração. Dissertação de Mestrado (Mestrado em Tecnologias Ambientais) Universidade Federal de Mato Grosso do Sul, Campo Grande, 2009.

MANDAI, P.. Modelo descritivo da implantação do sistema de tratamento de águas negras por evapotranspiração. Monitoria Canário Verde. Relatório técnico. Brasília: Associação Novo Encanto de Desenvolvimento Ecológico ANEDE, 2006.

MAROUELLI, W. A.; MALDONADE, I. R.; BRAGA, M. B.; SILVA $H$. R.. Qualidade e segurança sanitária da água para fins de irrigação. Brasília: Embrapa Hortaliças, 2014.

OLIVEIRA, G. D.; PEREIRA, I. A.; SOARES, A. F. S.; RAMOS, G. M. P. D.. Tratamento Domiciliar de águas negras: tanque de evapotranspiração. Revista Petra, v.4, n.2, 2018.

PAMPLONA, S.; VENTURI, M.. Esgoto à flor da terra. Permacultura Brasil. Soluções ecológicas, v.6, n.16, p.48, 2004.

PAULO, L. P.; BERNARDES, F. S.. Estudo de tanque de evapotranspiração para o tratamento domiciliar de águas negras. Belo Horizonte: UFMG, 2004.

SALA, F. C.; COSTA, C. P.. Retrospectiva e tendência da alfacicultura brasileira. Horticultura Brasileira, v.30, n.2, p.187-194, 2012.

SANTOS, R. S. S.; DIAS, N. S.; DUARTE, S. N.; LIMA, C. J. G. S.; FERNANDES, C. S.; MIRANDA, J. H.. Cultivo da rúcula em substrato de fibra de coco sob solução nutritiva salina. Cultura Agronômica: Revista de Ciências Agronômicas, v.27, n.1, p.12-21, 2018.

SCHERER, K.; GRANADA, C. E.; STULP, S; SPEROTTO, R. A.. Avaliação bacteriológica e físico-química de águas de irrigação, solo e alface (Lactuca sativa L.). Rev. Ambiente \& Água, Taubaté, v.11, n.3, p.665-675, 2016.

SILVA, J. L.; SILVA, E. S. B.; KOLLESKA, L.. Respostas produtivas de cultivares de rúcula em sistema hidropônico. Campo Digital, v.11, n.1, 2016.

SILVA, P. H. M.; POGGIANI, F.; GONÇALVES, J. L. M.; STAPE, J. L.. Volume de madeira e concentração foliar de nutrientes em parcelas experimentais de Eucalyptus grandis fertilizadas com lodos de esgoto úmido e seco. Revista Árvore, v.32, n.5, p.845-854, 2008.

SOUTO, R. A.. Avaliação sanitária da água de irrigação e de alfaces (Lactuca sativa L.) produzidas no município de Lagoa Seca, Paraíba. Dissertação (Mestrado em Agronomia) - Universidade Federal da Paraíba, João Pessoa, 2005.

SOUZA, O. B.; SATIRO, A.; MARTINS, B.; PRADO, C. Tratamento de água negra domiciliar através de bananeiras por tanque de evapotranspiração. Atas de Saúde Ambiental, v.6, p.235-248, 2018.

SOUZA, O. B.; SILVA, E. É.; SANAVRIA, A.; VITA, G. F.; MARINO, T. B.. Análise da Banana Pacovan Ken Cultivada em Tanque de Evapotranspiração e seu efluente. Ciência \& Desenvolvimento-Revista Eletrônica da FAINOR, v.12, n.2, 2019.

TACO. Tabela Brasileira de Composição de Alimentos. 4 ed. Campinas: NEPAUNICAMP, 2014.

TONETTI, A. L.; BRASIL, A. L.; MADRID, F. J. P. L.; FIGUEIREDO, I. C. S.; SCHNEIDER, J.; CRUZ, L. M. O.; DUARTE, N. C.; FERNANDES, P. M.; COASACA, R. L.; GARCIA, R. S.; MAGALHÃES, T. M.. Tratamento de esgotos domésticos em comunidades isoladas: referencial para a escolha de soluções. Campinas: Unicamp, 2018.

VALERIANO, T. T. B.; SANTANA, M. J.; MACHADO, L. J. M.; OLIVEIRA, A. F.. Alface americana cultivada em ambiente protegido submetida a doses de potássio e lâminas de irrigação. Irriga, v.21, n.3, p.620-630, 2016.

VILAR, J. B. B.; SANTOS, V. S.; DUARTE, A. E.; SANAVRIA, A.. Eficiência de um filtro de remediação (TEVAP) na remoção de poluentes em efluentes suínos. Vigilância Sanitária Em Debate: Sociedade, Ciência \& Tecnologia, v.7, n.2, p.94-101, 2019.

A CBPC - Companhia Brasileira de Produção Científica (CNPJ: 11.221.422/0001-03) detém os direitos materiais desta publicação. Os direitos referem-se à publicação do trabalho em qualquer parte do mundo, incluindo os direitos às renovações, expansões e disseminações da contribuição, bem como outros direitos subsidiários. Todos os trabalhos publicados eletronicamente poderão posteriormente ser publicados em coletâneas impressas sob coordenação da Sustenere Publishing, da Companhia Brasileira de Produção Científica e seus parceiros autorizados. Os (as) autores (as) preservam os direitos autorais, mas não têm permissão para a publicação da contribuição em outro meio, impresso ou digital, em português ou em tradução. 